\title{
Experience of Developing a Laboratory Base for the Study of Modern Microprocessor Systems
}

\author{
Oleg G. Avrunin \\ Department of Biomedical Engineering \\ Kharkiv National University of \\ Radio Electronics \\ Kharkiv, Ukraine \\ oleh.avrunin@nure.ua
}

\author{
Tatyana V. Nosova \\ Department of Biomedical Engineering \\ Kharkiv National University of \\ Radio Electronics \\ Kharkiv, Ukraine \\ tatyana.nosova@nure.ua
}

\author{
Valerii V. Semenets \\ Department of Metrology and \\ Technical Expertise \\ Kharkiv National University of \\ Radio Electronics \\ Kharkiv, Ukraine \\ valery.semenets@nure.ua
}

\begin{abstract}
A laboratory workshop was developed, consisting of a series of works aimed at studying and studying the principles of microcontroller programming, practical implementation of interaction with sensors, organization of work with input / output devices, and development of interface devices. By changing sensors that are connected to laboratory mockups or real equipment, and reprogramming the microcontroller system, you can perform laboratory work on almost all engineering profile courses.
\end{abstract}

Keywords_programming, microcontrollers, sensors, interface devices, layouts.

\section{INTRODUCTION}

The study of modern microprocessor systems and programmable logic integrated circuits cannot be qualitative without a laboratory base, which allows the student to develop practical skills and teach him to work with a real hardware, not computer simulators [1, 2]. Therefore, the authors' team developed a laboratory workshop consisting of a cycle of works aimed at studying and studying the principles of microcontroller programming, practical implementation of interaction with sensors, organization of work with information input / output devices and development of interface devices $[1,3]$. By changing sensors that are connected to laboratory mockups or real equipment, and reprogramming the microcontroller system, you can perform laboratory work on almost all engineering profile courses [4], for example, when training specialists in the field of biomedical engineering [5, 6] to develop modern medical appointments $[7,8]$.

\section{SCOPE OF THE DEVELOPED LAYOUTS}

These devices can be used (and are already used) as a laboratory base for basic disciplines related to the study of digital and microprocessor technology, and in special technical disciplines courses aimed at studying the principles of operation and the development of real microprocessorcontrolled devices [9-11]

Principles are being developed for the implementation of remote laboratory work. The main disciplines in which this laboratory base is already used are: "Digital devices and microprocessors", "Microprocessor technology", "Circuit design of microelectronic devices", "Automation of designing electronic devices and systems", "Designing specialized devices on microchips of grammable
logic","Application of microprocessor systems in medical equipment ","Application of microprocessor systems in home appliances","Pairing microprocessor systems with external devices" et al. Consider in more detail designed laboratory equipment.

\section{TECHNICAL CHARACTERISTICS OF ML-1}

The ML-1 laboratory layout for studying micro-controller control systems allows you to create flexible technical solutions for the development of digital devices with embedded control systems of low and medium levels of complexity and can be used in a wide range of household and medical devices, security systems, etc. The layout includes: the most common in Ukraine multifunctional 8-bit microcontroller by ATMEL AVR ATMEGA-128, an 8-bit LED display unit, user-programmable keys and a $4 \times 3$ matrix keyboard, additional 32 Mbit Flash-RAM external memory modules, DATA RAM 32K, 10-position Holtek HT-10 digital indicator, monochrome graphic display 240x128 LCD EPSON, RS-232 serial interface, 12-bit ADC and DAC modules, an external connector that allows you to connect non-standard devices, actuators and sensors iki. The microcontroller is programmed via the ISP programmer, JTAGICE interface with a debugger. The appearance of the laboratory layout is shown in Figure 1.

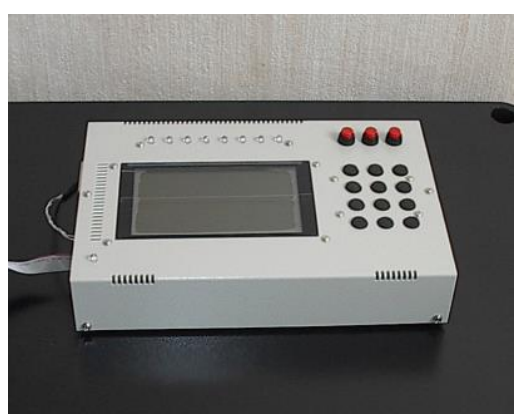

Fig. 1. ML-1 laboratory model

\section{TECHNICAL CHARACTERISTICS OF ML-2}

Laboratory layout ML-2 is designed to study the principles of the development of digital devices based on programmable logic chips. This model is used in disciplines that study digital circuitry and address issues related to the development of complete, full-featured digital devices and 
systems of high complexity, such as audio / video processors, modules for digital signal processing. The layout includes: FPGA (programmable logic integrated circuit), type FPGA by Altera ACEX EP1K100QC208, operating at $50 \mathrm{MHz}$, auxiliary microcontroller AT-Mega-128, additional memory block of 32 MB Flash RAM, EPSON 320x240 LCD display, video D / A $80 \mathrm{MHz}$, user-programmable LED modules, external high-power and keyboard; supports USB 2.0, RS232 and PS / 2 interfaces. Multiple FPGA configuration modes are supported: upload via USB interface, boot using Byte-Blaster, boot using Flash RAM, boot using an AVR microcontroller. The appearance of the laboratory model ML-2 is shown in Figure 2.

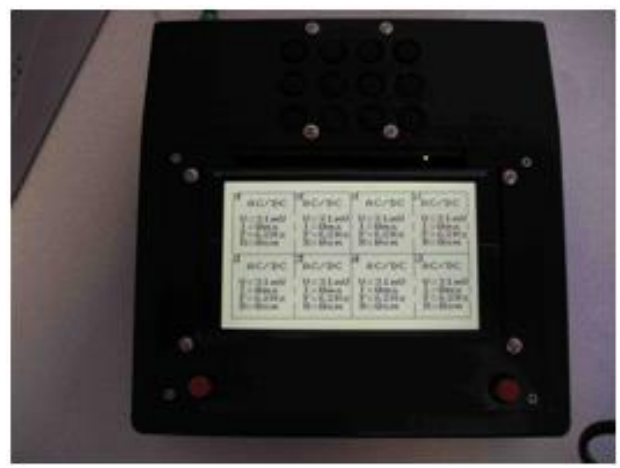

Fig. 2. ML-2 laboratory model.

\section{TECHNICAL CHARACTERISTICS OF ML-3}

Laboratory Layout ML-3 is designed to study the architecture of high-performance ARM microcontrollers. The structure of the ML-3 includes: ARM microcontroller company PHILIPS LPC-2106, operating at $50 \mathrm{MHz}, \mathrm{LCD}$ display with a resolution of $320 \times 240$, user-programmable LED modules, external pins and keyboard; Supports USB 2.0 and RS-232 interfaces. Supports multiple modes of flashing and debugging ARM microcontroller. The appearance of the printed circuit board of the laboratory layout ML-3 is shown in Figure 3.

\section{TECHNICAL CHARACTERISTICS OF ML-4}

Laboratory layout ML-4 is designed to study the principles of signal processing with the help of signal processors. This layout is applied in disciplines that deal with issues related to digital signal processing. The structure of the ML-4 includes: signal processor ADSP-BF532 BlackfinB ${ }^{\circledR}$ Processor, dynamic memory block $32 \mathrm{MB}(16 \mathrm{M}$ x 16-bit) SDRAM, 2 MB (512K x 16-bit x 2) FLASH, AD1836 $96 \mathrm{kHz}$ audio codec , ADV7183 video decoder, ADV7171 video encoder, ADM3202 for RS-232, USB 2.0, user-programmable LEDs, buttons and user-programmable pins.

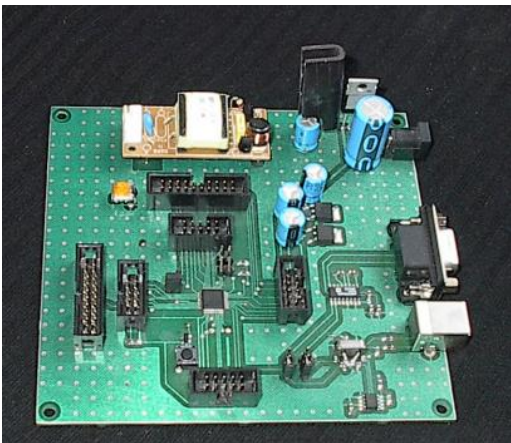

Fig. 3. ML-3 laboratory model.

The appearance of the printed circuit board of the laboratory layout ML-4 is shown in Figure 4.

When conducting an educational process in the system of secondary special, technical and higher education, in scientific departments, research institutes, the modernization of laboratory equipment and measuring equipment is relevant. The existing outdated equipment does not provide requirements for accuracy and reliability of measurements, it is morally and physically outdated, having repeatedly developed its resource. Often in the educational process in the universities of Ukraine are used devices that were manufactured in the 50-60s of the 20th century. Most of the measuring instruments do not pass the metrological tests, and the measurements obtained with their help contain a large proportion of errors and errors, and therefore require updating and replacement.

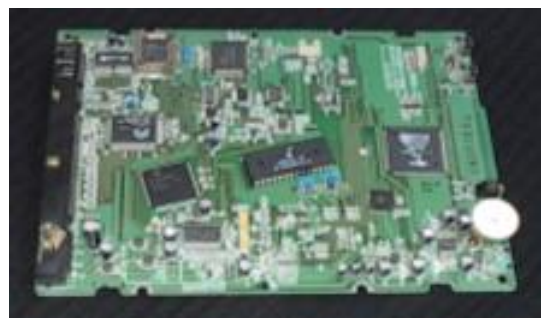

Fig. 4. ML-4 laboratory model

Professional measuring equipment, for example, manufactured under the brand name Tectronics and Ag-ilent, is very expensive and is not acquired even by large firms. In the same time, the emergence of new micro-controllers with a rich set of peripherals and support for a high-speed data exchange channel with a computer that do not require additional power supplies made it possible to create a compact device that combines all the above listed functions, at a price significantly lower compared to branded counterparts. As a result, a measuring complex was developed and manufactured, which contains 10 measuring devices in one housing:

- two-channel oscillograph, recorder;

- multimeter, which includes a voltmeter, ammeter, frequency meter, phase meter;

- functional generator;

- logic analyzer;

- logical generator; 
- $\quad$ spectrum analyzer,

which allows for a full cycle of work in the presence of one such device at the workplace. The developed device has small overall dimensions and is several times cheaper than the corresponding foreign analogues. Today, there are two versions of the measuring complex. In the first case, it is a complex oriented to work with software installed on a computer, in the second case it is an independent complex with its LCD display, fully functioning without a computer. The developed measuring complex IK- 1 is recommended for use in the educational process of technical-oriented universities.

\section{CONCLUSIONS}

In KNURE more than 200 such laboratory models are used for specialties and areas of training, such as information control systems and technologies; Computer systems and networks; system Programming; specialized computer systems; control systems; microelectronics and semiconductor devices; biomedical engineering, radioelectronic devices, systems and complexes; radio communications and television equipment; electronic household equipment; information security systems; metrology and measuring equipment. This equipment is introduced into the educational process of the following universities of Ukraine: Kharkiv National Polytechnic University "KPI"; Kiev University of Economics and Technology of Transport; Ukrainian State Academy of Railway Transport; Cherkasy State Technical University; Ivanofrankovsky National Technical University.

In addition, the use of this laboratory base allows to transfer the thesis design to a qualitatively new level, providing the opportunity to create real graduation projects, the output of which is not only an explanatory note with a theoretical presentation of the material, but also actual devices and mock-ups.

It should be noted that the problem of introducing such laboratory mockups requires appropriate preparation of teaching materials (lecture courses, instructions for practical training and laboratory workshops, as well as multimedia courses and electronic teaching aids for distance and distance learning). In this regard, there is a need to organize training of teaching staff, retraining courses and advanced training of specialists working in industry.

In conclusion, we can conclude that, based on the principle of remote programming of microcontrollers, it is possible to implement courses for remote laboratory work on the study of microprocessor control systems of various degrees of complexity. The perspectives of the work are the improvement of the software and hardware to expand the functional and educational capabilities of the remote laboratory workshop. The introduction of modern laboratory facilities in the educational process allows us to interest the modern student and teach him practical skills of working with real equipment.

\section{REFERENCES}

[1] V. Semenets, "Technical aspects for development laboratory base for learning FPGA and microcontroller systems," 2009 10th International Conference - The Experience of Designing and Application of CAD Systems in Microelectronics, Lviv-Polyana, 2009, pp. 145-145.

[2] V. Semenets, V. Kauk, O. Avrunin. "The advanced technology of remote training at the initial process" ["Vprovadjennya tehnologiy dystantsiynogo navchannya u navchalnii protses"], High School, 2009. - No. 5 .- P. 40- 45

[3] O. Avrunin, S. Sakalo and V. Semenetc, "Development of up-to-date laboratory base for microprocessor systems investigation," 2009 19th International Crimean Conference Microwave \& Telecommunication Technology, Sevastopol, 2009, pp. 301-302.

[4] O. Avrunin. The experience software-based design of virtual medical in trascopy systems for simulation study International Journal / O. Avrunin, L. Aver'yanova, V. Golovenko, O.Sklyar // Information Technologies and Knowledge. - 2008. - Vol.2. - P. 470-474.

[5] Sakalo S.M., Semenets V.V., Azarhov O.Yu. High frequencies in medicine (therapy and diagnostics): Teaching manual - X.: KNURE; Collegium, 2005. - 264 p.

[6] Y. Nosova, O. Avrunin and V. Semenets, "Biotechnical System for Integrated Olfactometry Diagnostics", Innovative technologies and scientific solutions for industries, vol. 0, no. 11, pp. 64-68, 2017. doi: 10.30837/2522-9818.2017.1.064.

[7] Avrunin OG, Faruk H. "On the possibility of using modern proportional electronics for modeling human breathing" Industrial voice and pneumatic. 2013. № 3 (41). Pp. 78-82.

[8] Y. Nosova, K. Faruk and O. Avrunin, "Radio Technology in Biomedical Investigation", Telecommunications and Radio Engineering, vol. 77, no. 15, pp. 1389-1395, 2018. doi: 10.1615/telecomradeng.v77.i15.90.

[9] Farouk, H., Avrunin, O. Comparison Discriminate Characteristics Between Modern TNDA-PRH Rhinomanometer And Previously Methodology. International Journal of General Engineering and Technology (IJGET) ISSN 2278-9928. - 2013 - Vol. 2, Is. 2, - P. 3950.

[10] O. Avrunin, N. Shushlyapina, Y. Nosova and O. Bogdan, "Olfactometry diagnostic at the modern stage", Bulletin of the National Technical University «KhPI» Series: New solutions in modern technologies, vol. 0, no. 12(1184), p. 95, 2016. doi: 10.20998/2413-4295.2016.12.13.

[11] Y. Nosova et al., "The use of statistical characteristics of measured signals to increasing the reliability of the rhinomanometric diagnosis", Photonics Applications in Astronomy, Communications, Industry, and High-Energy Physics Experiments 2016, 2016. doi: 10.1117/12.2248364. 